\title{
Caso Pacheco Léon y otros vs. Honduras
}

\section{Hechos}

El 23 de noviembre de 2001, poco antes de la medianoche, cuando Ángel Pacheco León estaba ingresando a su domicilio junto a su hijo Jimy, un hombre corrió hacia ellos, evitó que cerraran la puerta y disparó varias veces con un arma de fuego, produciendo la muerte del señor Pacheco León. Al momento de su fallecimiento Ángel Pacheco León era candidato, en el departamento de Valle, a primer diputado por el Partido Nacional de Honduras. Las elecciones se realizaron el 25 de noviembre de 2001, obteniendo la candidatura del señor Pacheco León los votos necesarios para que él accediera al cargo de diputado. A partir de la decisión de las autoridades partidarias, luego de reclamos de correligionarios del Partido Nacional, José Pacheco, hermano de Ángel Pacheco León, asumió como diputado en su reemplazo. E1 24 de noviembre de 2001 tres personas fueron detenidas como sospechosas de haber cometido el homicidio y prestaron declaración. No obstante, fueron luego desvinculadas del proceso, a partir de distintos actos judiciales, siendo el último que consta de 3 de mayo de 2002.

Además, en el curso de la investigación, que continúa abierta de acuerdo a información con que cuenta la Corte, se realizaron otras acciones. Entre ellas se encuentran las siguientes: recolección de evidencias en el lugar del delito; recepción de múltiples declaraciones; tres allanamientos; diversos peritajes, inclusive sobre material correspondiente a armas de fuego, e indagación sobre registros telefónicos. Varias declaraciones recabadas durante la investigación aludieron a circunstancias intimidatorias o de agresión que había sufrido el señor Pacheco León. Señalaron que personas vinculadas a la actividad política, inclusive algunas que eran agentes estatales, habían participado en dichas circunstancias. También se adujo a la intervención de un policía como supuesto autor material 
del homicidio. Las autoridades manifestaron que también recibieron información sobre la posible intervención de otras personas. Algunas personas que prestaron declaración indicando lo señalado manifestaron temor por su vida. En 2010, 2013 y 2015 el Ministerio Público solicitó la asignación de un equipo especial para investigar el homicidio, más de los hechos acreditados no surge que se atendiera favorablemente ese pedido.

\section{Fondo}

La Corte advirtió que pese a la destrucción y pérdida de ciertas muestras, y a que no se acredita la realización de ciertas diligencias, el Estado efectuó múltiples acciones de investigación, y recolectó material probatorio relevante No obstante, en cuanto al seguimiento de líneas lógicas de investigación, evaluó que hubo una conducta estatal negligente. Notó que hubo distintos indicios sobre la posible autoría del delito, varios de los cuales aludían a personas relacionadas con la actividad política del señor Pacheco León. Sin embargo, la Corte evaluó que el Estado no realizó conductas que podrían haber contribuido a esclarecerla.

En particular, observó que: a) diversas personas señaladas no prestaron declaración; b) recién se tomó declaración al policía preventivo antes aludido luego de un año y nueve meses después de que se señalara su supuesta intervención en el delito; c) no consta que se efectuaran medidas de "vigilancia” y "ubicación", consideradas pertinentes por las autoridades a cargo de la investigación respecto a ciertas personas posiblemente vinculadas a los hechos; d) no consta que se otorgara protección a declarantes, y e) aunque en 2010, 2013 y 2015 se advirtió la necesidad de un equipo especial para la investigación, no surge de los hechos que se atendiera ese pedido. Por otra parte, la Corte determinó que las actuaciones no se efectuaron en un plazo razonable. Consideró que aunque pueden existir elementos de complejidad en la investigación, ello no justifica la demora en las actuaciones, que lleva cerca de 16 años.

En ese período se advierten prolongados períodos de inactividad procesal. Por lo anterior, concluyó que el Estado ha violado los derechos a las garantías judiciales y protección judicial, consagrados en los artículos 25.1 y 8.1 Convención 
Americana en relación su artículo 1.1, en perjuicio de Blanca Rosa Herrera Rodríguez, Cinthia Mirella Pacheco Devicente, Tania Melissa Pacheco López, Bianca Gisselle Pacheco Herrera, Jimy Javier Pacheco Ortiz, Miguel Ángel Pacheco Devicente, Juan Carlos Pacheco Euceda, Andrea Pacheco López, María Otilia Pacheco, Concepción Pacheco, Blanca Pacheco, María Regina Pacheco, Santos Norma Pacheco, Marleny Pacheco Posadas, Elsa Yamileth Almendarez Pacheco, Jaqueline L. Almendarez Pacheco, José Pacheco, Francisco Pacheco y Jorge Pacheco.

\section{Reparaciones}

La Corte estableció que su Sentencia constituye por sí misma una forma de reparación y, adicionalmente, ordenó al Estado: i) adoptar, en un plazo razonable, las medidas necesarias para continuar la investigación; ii) investigar, en un plazo razonable, las causas del retraso procesal y de ser pertinente a los funcionarios involucrados en la investigación, y luego de un debido proceso, aplicar las sanciones correspondientes; iii) publicar la Sentencia de la Corte Interamericana y su resumen oficial; iv) establecer, en el plazo de un año, un protocolo de investigación diligente; v) establecer, en el plazo de un año, un programa o curso permanente obligatorio de capacitación y formación en derechos humanos, y vi) pagar las cantidades fijadas por daños materiales e inmateriales y por costas y gastos La Corte supervisará el cumplimiento íntegro de la Sentencia, en ejercicio de sus atribuciones y en cumplimiento de sus deberes conforme a la Convención Americana sobre Derechos Humanos, y dará por concluido el presente caso una vez que el Estado haya dado cabal cumplimiento a lo dispuesto en la misma. 
